\title{
Parenting Styles and Discipline Strategies of Immigrants: A Qualitative Study
}

\author{
Fawzia Reza \\ Diversity and Inclusion Coordinator, Office of Academic Excellence, American College of Education, Indianapolis, 46204, Indiana, \\ United States
}

Received October 9, 2020; Revised December 10, 2020; Accepted December 18, 2020

\section{Cite This Paper in the following Citation Styles}

(a): [1] Fawzia Reza, "Parenting Styles and Discipline Strategies of Immigrants: A Qualitative Study," Universal Journal of Educational Research, Vol. 8, No. 12B, pp. 8402-8410, 2020. DOI: 10.13189/ujer.2020.082646.

(b): Fawzia Reza (2020). Parenting Styles and Discipline Strategies of Immigrants: A Qualitative Study. Universal Journal of Educational Research, 8(12B), 8402-8410. DOI: 10.13189/ujer.2020.082646.

Copyright@2020 by authors, all rights reserved. Authors agree that this article remains permanently open access under the terms of the Creative Commons Attribution License 4.0 International License

\begin{abstract}
This qualitative study, conducted on 10 parents, with at least one child attending a K-8 classrooms, examines the experiences of immigrant parents as they raise their children in the United States. Participants selected were asked to identify which parenting strategy within Baumrind's discipline topology they most closely associate with. The study also examines the differences between how participants were raised in their home country, against how they raise their own children in the United States. The qualitative research design, and specifically a phenomenological inquiry, was considered appropriate because it allowed the researcher to capture participants' voices, thereby challenging normative, taken-for granted views on the topic of discipline techniques used by immigrant parents. Analysis of the responses demonstrates that immigrant parents proactively change their parenting style to comply with cultural norms of their new homeland. Understanding how discipline strategies of immigrant parents evolve will help them become more aware of their disciplining techniques and how these affect the social and emotional development of their children. The results will also assist educators and administrators to develop greater awareness of parenting styles of new immigrants and formulate policies to communicate more effectively with these parents. Further studies that compare the experiences of immigrant parents raising their children in the United States with other countries will be necessary to develop generalized recommendations and better understand how immigrant parents navigate child-rearing practices in these countries
\end{abstract}

Keywords Immigrant Parents, Discipline Strategies,
Child Rearing, Parenting Styles, Child Development, Culturally Diverse Students

\section{Introduction}

With increased globalization and disruptions due to terror, war, or natural disasters, the number of immigrants in Western countries is increasing dramatically. Within the United States, children of immigrants are the fastest growing segment of the population, and now account for nearly one quarter of all children under eight years old [1]. Glick Schiller, Basch \& Szanton [2] define transnationalism as a social process, in which immigrants develop and maintain "multiple relations" including familial, economic, social, organizational, religious, etc.across two or more societies: one being the home country and the other new nation of settlement. Many parents in the United States display their transnationalism as they communicate with family overseas or socialize with friends from their original culture.

Most immigrants adapt and assimilate into their new country over a trajectory that takes between one and two generations. One of challenges new immigrants face is how to adapt to cultural traditions and practices that might be incompatible with those in their home country. Specifically, immigrant parents of young children often struggle with raising their children in a new country within acceptable cultural norms which may conflict with the parenting style they were exposed to in their home country. 
Effective parenting requires active engagement to help children distinguish between acceptable and unacceptable behavior. Not all parents or parenting styles fall neatly into pre-defined categories [3] and some parents may occasionally deviate from or change their parenting styles. Nonetheless, the results from this study identify discipline strategies employed by immigrant parents, in the context of their transnational values and how these affect the social and emotional development of young children. Results will also assist immigrant parents and the educators and administrators who serve them to develop greater awareness of parenting styles of new immigrants and formulate policies to communicate more effectively with these parents.

\section{Literature Review}

It is necessary to understand whether child raising practices of immigrant parents conform to what is considered "normative" within their adopted culture and society [4]. Recently, there has been increased interest in research regarding transnational families who have members living abroad and how this impacts childrearing practices [5,6,7]. While corporal punishment (including hitting or spanking) has adverse effects on children's social and emotional development, many other discipline strategies are used by parents worldwide. It is also relevant to note that utilizing disciplinary techniques may have different effects on children across countries depending on what is considered normative within a given culture. For example, if a child perceives a particular discipline technique to be a normal consequence within a culture or a community, he or she is less likely to evaluate the parent's use of it as anomalous and the child is more likely to comply with the parent's demands, thereby reducing the occurrence of the negative behavior outcomes. On the other hand, children who are raised in cultures where parents discipline strategies are not utilized might resort to rebellious behavior and may exhibit more negative behavior.

In general, the U.N. considers corporal punishment of children as a form of violence, and such punishment is not consistent with the Convention on the Rights of the Child. Therefore, they recommend corporal disciplinary practices should be abolished. For example, the Global Initiative to End Corporal Punishment of Children (2016) prohibits all kinds of punishments that involve physical violence. As the results from the current study demonstrate, many immigrant parents who might have been exposed to corporal punishment while they were young, generally avoid punishing their children in the same manner as they assimilate into their home country. However, it is imperative that researchers and teachers also understand that certain immigrant parents who might consider corporal punishment normal may require additional guidance and assistance in creating an environment that promotes learning for their children.

Parenting practices are influenced by several contextual factors, including gender, the parents' own childhood experiences, their socio-economic background, education, and cultural systems. Harkness \& Super [8] explain this as the "cultural models that parents hold regarding children, families, and themselves as parents” (p. 62). Research on discipline typically focuses on parents' use of corporal punishment, because this kind of punishment is a scandalous form of discipline [9]. In a longitudinal study on different disciplinary strategies that are used by parents across different aged children [10], corporal punishment (e.g. spanking) ranked among the least common forms of punishment across both age groups studied. To better understand parental discipline strategies, research studies must broaden their focus on other forms of discipline that are used by parents when they discipline their children.

Sanchez [11] described that transnationalism embodies various systems or relationships that span two or more nations, including sustained and meaningful flows of people, money, labor, goods, information, advice, care, and love. Systems of power (i.e. patriarchy, Westernism) can be created, reinforced [or disrupted] in this process. (p. 493). As movement of people and cultures across the world increases, researchers must move beyond the framework of segmented assimilation to better understand how transnational families maintain their original values and goals while assimilating these with the expectations of the host country. By accepting and appreciating diverse viewpoints, researchers can explore a host of important questions, including how transnational people adjust, shift their sense of identity, and the focus of this study, adjust their child-raising practices.

Baumrind's theory of parenting styles [3] is considered a seminal work on parenting typologies and has been the basis of significant follow-on research [12,13]. Baumrind observed preschool aged children for 14 weeks. Based on her observations, she identified three groups of children each depicting a specific pattern of behavior. These include energetic-friendly, conflicted-irritable, and impulsive-aggressive. She concluded that these patterns were closely related to distinct parenting styles that define the behaviors and responsiveness of parents towards their children. Baumrind categorized these as authoritative parenting, authoritarian parenting, and permissive parenting [14]. The authoritative parental style is associated with parents who are highly involved with their children and grant them appropriate autonomy. Authoritarian parenting involves those parents who are not very involved in their children's upbringing and use coercive control, without granting children autonomy in decision making. Finally, permissive parenting is warm and accepting but uninvolved. Permissive parents tend to be either overindulgent or inattentive and, thus, engage in little control. 
Many researchers now accept that Baumrind's model provides a consistent framework to understand how children socialize within the United States [15]. The current study was also influenced by Baumrind's study of parental styles and the effects of these on the social development of the child.

While the genetic blueprint lays the basis of brain development, early life events significantly impact the pattern of brain architecture. The modification of the brain structure after birth is influenced by the relationships that the children establish with people in their immediate environment especially the parents since they are their children's first teachers and in the early years, children spend a lot of time in the home. The phrase parenting styles refers to those actions or behaviors that determine the emotional stage of parent-child interactions [16]. Positive social experiences give children a sense of security and encouragement to grow and develop. Therefore, bonding and partnership between children, parents and other key family members at home, provides a foundation for young children to discover, learn and develop. Parents are also responsible for the developing proper social etiquettes in children [17] with respect to "the acceptance of values, standards, and customs of society as well as the ability to function in an adaptive way in the larger societal context”, p. 284.

Transmigrant parents are often judged by their adopted society (either consciously or subconsciously) on how well they have assimilated into the fabric of their host country. Stereotyping refers to over-generalized representations of characteristics of people from a certain group based on a very limited data set. For example, Chua's book, Battle Hymn of the Tiger Mother [18] promoted a stereotype regarding Asian parents that closely resembled the authoritative style as described by Baumrind. The phrase Tiger Mom has become synonymous with American perceptions regarding the Chinese parenting style; an attempt to use American cultural beliefs to stereotype Chinese immigrants and their parenting style [19].

Notwithstanding Socolar et al's [10] findings that corporal punishment generally ranks as the least common, society may assume that certain immigrant parents use harsh physical punishments with their children. One reason is that the immigrants' child rearing practices might clash with the norms of the dominant culture, and the misunderstanding might cause educators to accuse parents of child abuse [20,21]. For example Fontes [21] suggested that some immigrant parents might engage in harsh physical punishment (such as slapping with the hands, and beating with an implement), even if they are "loving and devoted parents who practice traditional forms of child rearing that may include an authoritarian style and harsh corporal punishment, side by side with high levels of intimacy and support” (p. 31). Another study suggested that physically abusive corporal punishment was relatively common in immigrant Latino families, even though they had fewer incidents of domestic violence, alcoholism or other forms of child abuse [22].

Such generalizations often create challenges for new immigrants to develop a strong rapport with school administrators and their ethnically and culturally diverse families. Although school staff and administrators are not required to adapt and accept the child rearing protocols of culturally diverse families they serve, they are expected to be mindful when they interpret behaviors and practices by these families [21] and not generalize immigrant parents based on their birth of origin or any other feature that makes them set apart from mainstream society.

\section{Methodology}

This qualitative study examined the experiences of 10 immigrant parents raising their children within the United States. A qualitative research design, and specifically a phenomenological inquiry, was considered appropriate because it allowed the researcher to capture participants' voices, thereby challenging normative, taken-for granted views on the topic of discipline techniques used by immigrant parents. Creswell describes phenomenological inquiry as an approach that captures the "essence of human experience concerning a phenomenon, as described by the participants in the study” [23], p. 15.

The researcher adopted three specific selection criteria for prospective participants:

a). Since the study aims to understand why and how immigrant parents in the United States discipline their children, only immigrant parents who currently live in the United States were eligible.

b). Selected participants had at least one child attending an elementary school (K-8 grade).

c). Participants were required to have internet access for the anonymous interview.

A specific challenge was how to protect the privacy of the participants, in what some may consider a controversial topic. Therefore, a variation of the double-blind method was proposed to ensure that the researcher never became aware of the participant's identities. is necessary to understand whether child raising practices

\subsection{Study Participants}

Since the study aimed to understand why and how immigrant parents in the United States discipline their children, all participants were first born immigrants. First born immigrants are defined as those individuals who were born in another country but have become citizens of another country. Based on information volunteered during the interviews, participants included individuals from 
South Asia (Pakistan and India), Iran, Egypt, Nicaragua, and Portugal. All participants had a college degree, and at least one child currently enrolled in elementary school. Most were above 30 years old. 9 participants were females while one participant was a male.

The study was conducted in 3 phases:

\subsection{Phase 1}

The researcher sent an email to a group of people asking if they would be interested in participating in the study. She utilized snowball sampling to solicit suggestions regarding additional participants from the respondents. Once she had received a enough affirmative responses via email, she sent a background questionnaire to all respondents who had expressed interest in participating in the study. The questions included pre-set responses that participants could choose from (i.e. similar to the Likert scale).

\subsection{Phase 2}

Once the researcher received responses from the survey, she assigned a colleague who was not affiliated with this study to select 10 participants who had agreed to the interview through a random selection procedure. For example, if 50 parents responded to the initial survey questionnaire, she randomly drew the names of 10 participants from a closed container that contained all the 50 names. This ensured that all participants had an equal chance of being selected. The names of the selected participants were not revealed to the researcher, instead her colleague assigned each of these participants unique pseudonyms and scheduled skype interviews with the selected participants and the researcher. The colleague forwarded only the assigned pseudonym and the interview time to the researcher and did not participate in the interview. At no point was the researcher aware of the identity of the study participants. The interviews were conducted only once.

\subsection{Phase 3}

The researcher utilized the Skype platform to conduct a semi-structured interview spanning about 45 minutes with each participant to explore their perceptions regarding discipline strategies, parenting style and their child rearing practices. Specifically, the interview included preapproved questions (via an Institutional Review Board process) regarding disciplinary strategies utilized by the study parents, discipline strategies used on the parents when they were children, and whether their attitudes and practices to raising children had changed after they immigrated to the United States. The interview was supplemented with probing questions to elicit more detailed responses during the interview.

\subsection{Institutional Review Board Approval}

The proposed methodology received approval from the Institutional Review Board (IRB) of the researcher's organization. Pursuant to their requirements, before every interview, the researcher explained the purpose of the study to the participant and informed them that they did not have to respond to any question they were not comfortable with and they would still be eligible to participate in the study if they skipped certain questions.

\subsection{Ethical Considerations}

Interviews were conducted via Skype (audio) and recorded for accuracy. The participants were aware that they were being recorded. They also understood that their participation was completely voluntary and that they were free to withdraw from the study at any time. To protect confidentiality of collected data, the researcher transcribed the audiotapes herself, and the tapes were destroyed immediately after transcription. The consent forms were always kept separate from the data. Whenever quotes from the participants are included, they are represented by a letter (i.e. A through J), which only corresponds to the order in which they were interviewed.

\section{Data Analysis}

The recorded interviews were transcribed and analyzed in a systematic and consistent manner. The researcher read and re-read each interview transcript and highlighted the words, phrase or sentences that seemed relevant to the topic of the study. These became the basis for coding the data utilizing the 'constant comparison' method to identify emerging common codes as well as anomalies across the responses [24]. Once the codes were identified through iterative analysis, the researcher assigned broader themes to highlight the findings.

\subsection{Establishing Methodological Rigor}

\subsubsection{Thick Description}

According to Lincoln and Guba [25], transferability and external validity can be achieved through a thick (i.e. rich) description. The researcher purposely designed the interview protocol in a way that the study participants could provide insightful and comprehensive responses regarding the child rearing technique. This allowed her to understand the differences between how the study participants were raised in their home country with how they raise their children in their new homeland.

\subsubsection{Low Inference Descriptors}

Using words and phrases that are identical or similar to what the subjects said in the study has reduced the 
chances of an incorrect interpretation of the subject's intent. The researcher highlighted the exact words of the interviewee to identify many of the themes to ensure that the data analysis was not influenced by subjective or biased inferences.

\section{Results}

Five themes emerged from the analysis of the data collected.

1. Association with Baumrind's parenting style

2. Parents' perspective regarding the importance of discipline

3. Effective and ineffective discipline techniques

4. Childhood experiences with being disciplined

5. Cultures that are more accepting of discipline

\subsection{Association with Baumrind's Parenting Style}

All parents $(\mathrm{n}=10)$ interviewed for this study identified themselves as authoritative parents. Responses from participants highlighted that they are very engaged and involved in their children's upbringing and want their children to develop in the cognitive, emotional and social domains, while maintaining a warm relationship with them. Parent D explained "I am involved with my kids and always I praise them, and I encourage them, and I have a good relationship with them". Parent F had similar opinions, and shared that "I am very involved in their rearing and childhood... I want to enjoy my kids...I give them a lot of autonomy. They need to make decision and my thinking is that if they make mistakes in front of me, we have a chance to correct them".

Parent C recognized that children in the United States generally have more freedom and opportunities, but she served as a gatekeeper to ensure her children made correct decisions.

I am not doing something that I don't agree with, and I do not give my control to them. But besides, they have freedom for so many things that they like to do. Like if I want to take them to one class, they have a freedom to say yes or no. But like if they want to do something, like they do not want to go to school, I am not agree with that, I will not allow it.

\subsection{Parents' Perspectives Regarding the Importance of Discipline}

All participants $(n=10)$ agreed that discipline was an important component of their child rearing strategy. Parent I explained that disciplining is "partially from the way I was brought up. I mean it is a big part of the story that for sure." Specific responses regarding why parents believed that they should discipline children varied across participants. For example, Parent F shared;

I don't think not disciplining them, not providing them feedback is something that is wrong, it is also appropriate", whereas another stated, "they don't know what they are doing. We have to tell them what is right for them and what is not right for them and why not

Disciplining children because it "can build his character" was also reported by several participants. Parent G opined, "if you don't correct their mistakes at an early age, it lingers on and creates a problem later in life for themselves and for people around them.” Parent J explained:

I think children thrive with structure. I firmly believe that they need boundaries to feel safe and secure so providing them leeway. I think it is important to give them the benefit of the doubt and trust them and provide them some liberty, a framework if you will. But certainly, they need to have an understanding of the consequences when they break the rules or do something that is against the values of the family or what they have been told not to do.

\subsection{Effective and Ineffective Discipline Techniques}

Opinions regarding effective and ineffective discipline techniques were solicited from study participants. Parent $\mathrm{G}$ described their approach:

Talking to them [the children], telling them that this is not acceptable. First giving them a warning and if they still continue with that problem that they actually taking away things that they like for you know depending on their how intense the problem is from a day to a week to a month. For the younger one, I have taken TV for a day or you can't go over to a friend's house or your friend cannot come over. Something that she really likes to do and I feel that it really works

Parent E shared a similar opinion:

... talking to them, giving them a second chance, making them understand that hey mistakes happen, as long as you learn from it, you know we are good. And also to take a creative approach to it. Maybe I have never tried that but something that I have read about. It is telling the child, what if you were in my position, what you would do. Like reverse the roles. This helps them to see from our perspectives well and other's perspective. To see if he was your friend, what do you think the parents should do? What do you think would be fair? Talking and explaining why and why not

Using rewards was also listed as an effective discipline technique. For example, Parent A stated that she gives her child, a "tiny piece of chocolate" when her child listens to her requests.

Parents also discussed ineffective discipline strategies. Parent B succinctly described an ineffective discipline technique as one that centers "around punitive consequences that are unrelated to what they did. We try to use fear.” Parent A expressed a similar opinion, but linked it back to her own experiences in her home country, "in my country of birth, there is a lot of what I call "negative 
discipline” a lot of a lot of yelling, a lot of hitting, a lot of fear instilled in the children.” Parent J indicated that "when I raise my voice and scream, it is not effective because they shut down and what actually happens is that they don't just shut down, but they react in a similar way. It is not a productive conversation."

Corporal punishment was uniformly reported as ineffective. Parent E stated:

Corporal discipline doesn't work for me because it scars the child you know and it scars them physically and emotionally and then in the long run when they become adults, it becomes very hard for them to overcome that. So I don't think that corporal discipline is the way to go. The other humiliation is not good either, putting them in the corner, isolate them is not good. It is like sending them to jail or something. So that is not good either

Parent H opined,

I will say that hitting will be ineffective because once they stop talking to you and they will be more scared from you and if we are going to tell mom, she may be mad on us or she may hit us, so I think if you want open kind of person to them, if you listen to them, talk to them, it is much better

\subsection{Parental Experiences with Discipline During Their Own Childhood}

All participants freely shared how they were disciplined when they were children. For example, Parent B described how fear of being punished was detrimental to her relationship with her parent. She shared

...because we were in fear of one parent and the other parent sort of provided the structure that we grew up under and the fear of one parent sometimes drove the parenting of the other parent. In ways that sometimes were damaging to the relationship

Parental discipline strategies changed as children grew older. Parent A shared

My mother was very quiet, and it was very much left to my father more to do the disciplining. He did hit. To me that was very ineffective. For example, if I accidently woke him up or we were too loud playing or if we were playing too loudly, me and my sister like outside the door he was trying to take a rest, right. He might come out and hit us and so that would be an example. Umm and I was younger, and I was better at hiding so unfortunately my older sister bore the brunt. And because of that, you know even though my dad was wonderful, and a loving dad in many, many ways, and as we got older, especially when we were teenagers, he didn't do this and would sit down with us and more and discuss why we did certain things. His strategy seemed to change as we got older

In some families, other family members disciplined the children. Parent $\mathrm{C}$ said that when she was young, she was "beaten" by her brother who was "in charge" of her. She recalled one instance wherein her brother asked her to re-write all her homework.

It was like 150 pages and he gave me one week to be finished. Like in the last day, he came home from work, it was 5 o'clock and he asked me 'are you done?' I said I have one page. It was like 150 page and I wrote all of them and I told him I had one page, he told me you didn't finish it. And he beat me a lot

Parent G said that while her parents did not punish her, her uncle "would put me on top of one of the cupboards and I had to sit there, so it was more of a time out and it worked."

Parents also utilized facial expressions as a discipline strategy. Parent E stated,

My dad just by looking at me you know certain way, I knew that was just that, he didn't even need to slap me or anything and I could see in his eyes the disappointment so nothing with a belt or anything. And then they would also try and talk to us but sometimes the technique of talking the negative talk like you don't do this, you will never going to be good like the I don't think I like that but I use it sometimes and that is the bad part and I try to change you know, the negative talk cause it makes you feel like as I said that you are not good. I don't think it is our role to tell our kids. Of course, we cannot lie to them, yeah you are the best, you are the best, but you cannot either make them feel like they nobody

\subsection{Cultures that are More Accepting of Discipline}

When asked to discuss if certain cultures were more accepting of discipline, responses varied. Parent F said,

I think certain cultures, especially older cultures have nomadic cultures have a lot more patience with children and lot of wisdom so to speak. But some kind of course correction is necessary. I mean in all cultures and I think all cultures have different ways of doing it

Participants generally believed that Saudi Arabians, Asians, Pakistani, Indians, Chinese, Russians, Mexicans, Portuguese. Latin Americans, Middle Eastern, Eastern Europeans, Egyptians and Far East Asians are more accepting of harsher disciplinary methods.

\section{Discussion}

As immigrant parents adapt to their new homeland, they are often faced with stressors such as learning a new language and integrating into the customs and traditions of their host country. Many immigrants are also cognizant that their parenting practices might be considered archaic or offensive in their new country, and they might be required to embrace new practices, consistent with societal expectations [26]. Some immigrant parents are also challenged in how to adapt and learn the parenting and child rearing strategies in their new countries [27]. In 
response, immigrant parents might engage in a form of hybridized parenting, where they continuously negotiate between the cultural norms of their home country against the norms of their host country. Their concerns can be ascribed to the "determination and hesitation, expectations and apprehensions, and dreams and worries" [28], p. 489, of what to expect in their new homeland. This is consistent with previous research conducted on immigrants' childrearing styles [29,30].

By generalizing parents based on their ethnicity, there is a risk of promoting a viewpoint that is most consistent with tourist multiculturalism [31], such that the differences between parents is not recognized. Therefore, it is important that a stereotype viewpoint is not promoted. The researcher endeavored to identify the parenting topology [3] immigrant parents most closely associate with, how they retrospectively reflect on their own childhood, and adapt their child rearing practices after moving to the USA. Not all parents or parenting styles fell neatly into the three categories listed by Baumrind. Results demonstrate that some immigrant parents may occasionally change their parenting styles, depending on the circumstances.

Yearwood [32], believes that parenting is "historically bound, culturally organized, and responsive to meeting current environmental demands" (p. 7). Based on this definition, parenting styles should not be static and should evolve with cultural and societal expectations. Parent E highlighted this very well:

you know as a human beings, we all try to evolve. You know society evolves as well, so you know we have to evolve with it. And of course, your parents, you know they had the tools available at the time...nowadays the techniques that we have you know either because there is more research, there are more investigations, there are more writings and readings that you can do to apply new techniques and specifically because there is diversity in the world and it is so expanse

As described above, educators in western societies might assume that immigrant parents generally use harsher disciplinary techniques on their children than what is considered normative in Western society. Results from this study appear to challenge these stereotypical assumptions. Although all participants agreed that some form of discipline was necessary for their children, no participant utilized corporal punishment, and many did not agree that harsh disciplinary strategies were effective. The results also highlight how transnational practices guide immigrant parents to raise their children in the United States. Parent F succinctly described this:

when you come from a different country you have certain inherent knowledge base that you are bringing, certain ways of approaching a problem and so on and so forth but then you come into a brand new country and you feel a little lost and you sort of start from scratch and think about how whatever you have learnt does apply and

\section{sort of apply and what to keep and what to not to keep}

Although many immigrant parents had been themselves exposed to corporal punishment, none of the study participants utilized this is a discipline strategy for their own children. All participants stressed that it was important to nurture their children and teach values and appropriate behavior for their adopted society, so that they could become competent adults. This contradicts findings from Snyder and Bub [33], who suggested that parents who experienced corporal punishment when they were children tend to use corporal punishment as a discipline technique with their own children. However, their study did not focus specifically on immigrant parents and therefore the contradiction might be resolved by understanding that immigrant parents actively adapt their parenting style to conform to societal expectations.

Parenting styles influence children's social and emotional development and better understanding these may help immigrant parents become more aware of their disciplining techniques, in the context of their transnational values and experiences. Several research studies have demonstrated that ineffective parenting contributes to negative emotional and social growth during adolescence. For example, authoritarian parents do not communicate warmly with their children and do not demonstrate love or compassion towards them. This can adversely affect the children's development and relationship skills as they interact with their peers. Sharing the findings from this study with such parents might assist them to become more aware of the impact of their parenting practices.

It is significant that while immigrant parents maintain transnational ties, they are very willing to adapt and assimilate to the norms of their new homeland. For example, Parent B opined:

I think one thing that is different in disciplining immigrant children versus disciplining native-born children is that balancing the culture that you are trying to walk in raising a child who is a first-generation child is different because their identity is literally torn in two. In my case, that being that child whose identity was split, I am parenting a child whose identity is not split. They know who they are, where they come from and they know what they can count on and kind of their given society factors So I think that dynamic kind of changes things because the child's own understanding of their identity I think impacts the way what is effective as far as discipline strategy.

\section{Implications}

Findings from this study have implications for parents as well as teachers and school administrators.

\subsection{For Parents}


This qualitative study has highlighted how varying parenting styles influence children's social and emotional development and may help parents become more aware of their disciplining techniques in the context of their parenting style and how these might hinder or facilitate the development of their children.

\subsection{For Teachers and Administrators}

The American School Counselor Association's Ethical Standards for School Counselors [34] recommends that professional school counselors must "stay abreast of current research and to maintain professional competence in advocacy, teaming and collaboration, culturally competent counseling and school counseling program coordination..." (p.12). Without cultural competence and lack of cultural relevant pedagogy, educators may view child rearing practices of immigrant parents on false cultural assumptions, which may lead to misunderstandings and negative relationships between parents and educators [21].

Findings from this study will provide teachers an insight into the acculturation and assimilation process among immigrant parents in the United States. Some teachers erroneously assume that immigrant parents generally use harsher disciplinary techniques on their children. Results from this study might challenge such stereotypical assumptions. The study will also assist teachers to develop better rapport with immigrant parents so that they can assist them in their cultural transitions as families adapt and assimilate into a new country.

School administrators can also utilize the results to develop a better understanding of culture and child rearing practices of immigrant parents and their families, thereby reducing the gaps in their knowledge as they interact with them. qualitative study has highlighted how varying parenting styles influence children's social and emotional development and may help parents become more aware of their disciplining techniques in the context of their parenting style and how these might hinder or facilitate the development of their children.

\section{Limitations and Recommendations for Future Research}

This study has compared the experiences of 10 immigrant parents raising their children within the United States. As with all similar studies, there are certain limitations. Due to the limited number of participants, the findings cannot be broadly generalized. The reliability and validity of self-reported practices has been a concern in social research [35]. The data for this study consisted solely of parents self-reporting their parenting styles. Some participants may not have provided accurate information regarding how they discipline their children.
Further studies that compare the experiences of immigrant parents raising their children in the United States with other countries will be necessary to develop generalized recommendations and better understand how immigrant parents navigate child-rearing practices in these countries.

\section{REFERENCES}

[1] Fortuny K, Hernandez D. J, and Chaudry, Online available from

https://www.urban.org/sites/default/files/publication/29106 /412203-Young-Children-of-Immigrants-The-Leading-Edg e-of-America-s-Future.PDF

[2] N. Glick Schiller, L. Basch, C.B. Szanton. Towards A Transnational Perspective on Migration: Race, Class, Ethnicity and Nationalism Reconsidered. New York Academy of Sciences. New York, 1992.

[3] D. Baumrind. Childcare practices anteceding three patterns of preschool behavior, Genetic Psychology Monographs, Vol. 75, No.1, 43-88.

[4] K. Deater-Deckard, K.A. Dodge. Externalizing behavior problems and discipline revisited: Nonlinear effects and variation by culture, context, and gender, Psychological Inquiry, Vol. 8, No. 3, 161-175.

[5] F. Borraz. Assessing the impact of remittances on schooling: The Mexican experience, Global Economy Journal, Vol.5, No 1, 1-30.

[6] L. Schmalzbauer. Searching for wages and mothering from afar: The case of Honduran transnational families, Journal of Marriage and Family. Vol. 66, No. 5, 1317-1331.

[7] J. Dreby. Children and power in Mexican transnational families, Journal of Marriage and Family, Vol. 69, No. 4, 1050-1064.

[8] S. Harkness, C. M. Super. Themes and Variations: Parental Ethnotheories in Western Cultures, Parenting Beliefs, Behaviors, And Parent-Child Relations: A Cross-Cultural Perspective. Rubin, K. H., \& Chung, O. B. (Eds.) Psychology Press. London, 2013.

[9] E. T. Gershoff, A. Grogan-Kaylor. Spanking and child outcomes: Old controversies and new meta-analyses, Journal of Family Psychology, Vol. 30, No. 4, 453-469.

[10] R. R. Socolar, E. Savage, H. Evans. A longitudinal study of parental discipline of young children, Southern Medical Journal, Vol. 100, No. 5, 472-477.

[11] P. Sanchez. Urban Immigrant Studies: How transnationalism shapes their world learning, The Urban Review, Vol, 39, No.5, 489-513.

[12] Coste B, Online available from http://www.positive-parenting-ally.com/3-parenting-styles. html

[13] S. Sarwar. Influence of parenting style on children's behaviour, Journal of Education and Educational 
Development, Vol. 3, No. 2, 222- 249.

[14] S. Kuppens, E. Ceulemans, Parenting styles: A closer look at a well-known concept, Journal of Child and Family Studies, Vol. 28, No. 1, 168-181.

[15] N. Darling, L. Steinberg. Parenting style as context: An integrative model, Psychological Bulletin, Vol.113, No 3, 487-496.

[16] R. S. Siegler, J. S. DeLoache, N. Eisenberg. How Children Develop. Macmillan. London, 2006.

[17] J. E. Grusec, P.D. Hastings. Handbook of Socialization: Theory and Research. Guilford Publication. New York, 2007.

[18] A.Chua. Battle Hymn of the Tiger Mother. Bloomsbury Publishing, London, 2012.

[19] S. Wang, The “Tiger Mom”: Stereotypes of Chinese Parenting in The United States, Online available from https://wp.nyu.edu/steinhardt-appsych_opus/the-tiger-mom -stereotypes-of-chinese-parenting-in-the-united-states/

[20] I. Earner. Immigrant families and public child welfare: Barriers to services and approaches for change. Child Welfare New York, Vol. 86, No.4, 63-91.19-23, 2008.

[21] L. A. Fontes. Child discipline and physical abuse in immigrant Latino families: Reducing violence and misunderstandings. Journal of Counseling \& Development, Vol. 80, No.1, 31-40

[22] A.J. Dettlaff, M. A. Johnson. Child maltreatment dynamics among immigrant and U.S. born Latino children: Findings from the national survey of child and adolescent well-being (NSCAW), Child and Youth Services Review, Vol. 3, 936-944.

[23] J. W. Creswell. Research Design: Qualitative, Quantitative Approaches (2nd ed.). Sage Publishers, Thousand Oaks, CA, 2003

[24] M. D. LeCompte, J. Preissle. Ethnography and Qualitative Design in Educational Research. Academic Press. San Diego, CA
[25] Y. S. Lincoln, E.G. Guba, E. G. Naturalistic inquiry. Sage Publishers, CA

[26] P. Sanagavarapu. What does cultural globalization mean for parenting in immigrant families in the 21st century? Australasian Journal of Early Childhood, Vol. 35, No. 2, 36-42.

[27] M. H. Bornstein, Y. Bohr. Online available from https://www.child-encyclopedia.com/immigration/accordin g-experts/immigration-acculturation-and-parenting

[28] J. Li. Expectations of Chinese immigrant parents for their children's education: The interplay of Chinese tradition and the Canadian context, Canadian Journal of Education, Vol. 26, No. 4 477-494

[29] D. Abbott, P. M. Gupta. Influence of American Culture on East Indian Immigrants' Perceptions of Marriage and Family Life. In R.L. Dalla, J. Defrain, J. Johnson, And D. A. Abbott (Eds.), Strengths and, Challenges of New Immigrant Families (pp.93-U6). Lexington Books, New York, 2009

[30] R. Londhe. Decisions About Child Rearing Practices in First Generation Asian Indian Immigrants. In R.L. Dalla, J. Defrain, J. Johnson and D.A. Abbott (Eds.), Strengths and Challenges of New Immigrant Families (pp. 217-239). Lexington Books, New York, 2009.

[31] L. Derman-Sparks. Revisiting multicultural education: What children need to live in a diverse society, Dimensions of Early Childhood, Vol. 22, No. 1, 6-10.

[32] E. Yearwood. Growing up children: Current childrearing practices among immigrant Jamaican families, Journal of Child and Adolescent Psychiatric Nursing, Vol. 14, No. 1, 7-17.

[33] Snyder A, and Bub S, Online available from https://www2.uwstout.edu/content/rs/2008/19discipline\%2 0for\%20publication.pdf

[34] American School Counselor Association, Online available from https://dese.mo.gov/sites/default/files/appendixI.pdf

[35] E. L. Grigoerenko, R. J Sternberg. Elucidating the etiology and nature of beliefs about parenting styles, Developmental Science, Vol. 3, No. 1, 93-112. 